\title{
Silicon fertilisation affects morphological and immune defences of an insect pest and enhances plant compensatory growth
}

\author{
Tarikul Islam $^{1,2}$ D $\cdot$ Ben D. Moore ${ }^{1} \cdot$ Scott N. Johnson ${ }^{1}$
}

Received: 1 August 2021 / Revised: 31 December 2021 / Accepted: 4 January 2022 / Published online: 13 January 2022

(c) The Author(s) 2022

\begin{abstract}
Herbivorous insects have evolved various anti-predator defences, including morphological, behavioural, and immune defences, which can make biocontrol of herbivorous pests challenging. Silicon ( $\mathrm{Si}$ ) accumulation in plants is a potent physical defence against mandibulate insects. However, it remains uncertain how Si affects the anti-predator defences of insect herbivores and plant defences following herbivory. We grew the model grass, Brachypodium distachyon, hydroponically with $(+\mathrm{Si})$ or without $(-\mathrm{Si}) \mathrm{Si}$ and investigated the plant-mediated effects of $\mathrm{Si}$ on the anti-predator defences of the cotton bollworm, Helicoverpa armigera, integrating morphological (i.e. integument resistance and thickness), behavioural, and immune defences. We also examined the effects of Si on plant compensatory growth and leaf trichome production. Larval growth, leaf consumption, and integument resistance were lower when feeding on $+\mathrm{Si}$ plants compared to when feeding on $-\mathrm{Si}$ plants. Larval integument thickness, defensive behaviours, haemocyte density, and lysozyme-like activity in the haemolymph were unaffected by Si. Larvae fed on $+\mathrm{Si}$ plants had higher haemolymph phenoloxidase (PO) and total-PO activities than larvae fed on -Si plants, although this did not enhance the melanisation response of larvae. Furthermore, Si supplies increased plant compensation for herbivory and constitutive trichome production, whereas herbivory induced trichome production only on -Si plants. We provide the first evidence for plant-mediated effects of Si on anti-predator defences of an insect herbivore. We suggest that the lower integument resistance of larvae when feeding on Si-supplemented plants could contribute to their vulnerability to natural enemies and that high PO activity may impose fitness costs (e.g. delayed development).
\end{abstract}

Keywords Silicification · Helicoverpa armigera Anti-predator defence · Defensive behaviours · Induced plant defence · Leaf trichomes

\section{Introduction}

The nutritional quality and physical and chemical defences of plants can substantially impact the performance and fitness of herbivorous insects (i.e. bottom-up effects) (Singer and Stireman 2005; Vidal and Murphy 2018). Changes in performance and fitness can impact the anti-predator defences of insect herbivores, which in turn can affect their

Communicated by Peng Han.

Tarikul Islam

tarikul.islam@westernsydney.edu.au

1 Hawkesbury Institute for the Environment, Western Sydney University, Locked Bag 1797, Penrith, NSW 2751, Australia

2 Department of Entomology, Faculty of Agriculture, Bangladesh Agricultural University, Mymensingh 2202, Bangladesh vulnerability to natural enemies such as predators and parasitoids (top-down forces) (Forkner and Hunter 2000; Pekas and Wäckers 2020). For example, feeding on high-quality host plants can enhance insect immune defences such as encapsulation and melanisation of invaders (i.e. parasitoid eggs) (Diamond and Kingsolver 2011; Gherlenda et al. 2016). Moreover, insect herbivores can exploit plant defence chemicals (e.g. secondary metabolites) to self-medicate (Garvey et al. 2021) or to defend against their enemies via sequestration (Winde and Wittstock 2011).

Among insect pests, lepidopteran larvae encounter extensive top-down pressures (Bernays 1997) and are often managed with biological control (Stiling and Cornelissen 2005). As counteradaptations, larvae have evolved a range of anti-predator defences including morphological, behavioural, chemical, and immune defences (Greeney et al. 2012; Sugiura 2020). For instance, thicker integuments or larger body spines can function as morphological defences against 
parasitoids (Gross 1993). Moreover, larvae can show evasive behaviours including thrashing, twisting, or dropping to avoid enemies, and aggressive behaviours including headrearing, regurgitating, or biting while encountering enemies (Greeney et al. 2012; Gross 1993). However, after successful attacks by pathogens or parasitoids, larvae mostly rely on immune defence driven by cellular and humoral mechanisms. Haemocytes, the circulating haemolymph cells in larvae, can cause phagocytosis of microorganisms and encapsulation of foreign entities such as parasitoid eggs or larvae (Lavine and Strand 2002). Humoral responses include the actions of phenoloxidase (PO), a key enzyme that regulates melanisation of invaders and wound healing (Eleftherianos and Revenis 2011), and lysozyme activity that degrades bacteria and fungi (Moreno-García et al. 2013).

Plant defence against herbivores comprises resistance (e.g. physical and chemical barriers to herbivory) and tolerance to attack, including compensatory growth in response to herbivory (Núñez-Farfán et al. 2007). Both physical and chemical defences in plants can be expressed constitutively or induced when challenged by herbivores (Gatehouse 2002). Silicon ( $\mathrm{Si}$ ) accumulation in plants is recognized as an effective physical defence against chewing herbivores (Massey and Hartley 2009; Reynolds et al. 2016), particularly in grasses including cereal crops, as they possess limited secondary metabolite defences and can accumulate relatively higher amounts (up to $10 \%$ of dry weight) of $\mathrm{Si}$ (Moore and Johnson 2016; Vicari and Bazely 1993). Plants deposit silica $\left(\mathrm{SiO}_{2}\right)$ in tissues, including physical defence structures (e.g. trichomes), following active uptake or passive absorption of aqueous orthosilicic acid via roots and transportation via xylem (Ma and Yamaji 2006; Mandlik et al. 2020).

Silicification of plant tissues makes them tougher and abrasive and hence less masticable and digestible for chewing herbivores (Massey and Hartley 2009). Silicified tissues can wear down the mandibles of larvae when feeding (Massey and Hartley 2009) and silicified trichomes can cause gut damage when passing through the digestive tract (Andama et al. 2020). Chewing insects generally feed less on silicified plants and have retarded growth because of reduced nutrient assimilation (Massey and Hartley 2009). However, it remains uncertain whether malnourishment caused by siliceous plants compromises the anti-predator defences of insects. This question is of interest, as $\mathrm{Si}$ accumulation by plants has recently been shown to promote the attraction of natural enemies of herbivores (Islam et al. 2022; Liu et al. 2017) and impact tri-trophic interactions by changing host insects' body size (Hall et al. 2021). Moreover, research on antiherbivore Si defences has mostly focused on plant resistance, with the role of $\mathrm{Si}$ in plant compensation or tolerance relatively neglected. Furthermore, herbivory often induces increased Si accumulation in plants (Islam et al. 2020;
Massey et al. 2007); however, how Si induction impacts the production of other inducible defence structures such as trichomes remains understudied, although there are reports that Si can enhance constitutive trichome production (Biru et al. 2021; Johnson et al. 2021a).

To the best of our knowledge, the plant-mediated effects of $\mathrm{Si}$ on anti-predator defences integrating morphological, behavioural, and immune defences of herbivorous insects have yet to be investigated. We grew the model grass, Brachypodium distachyon, hydroponically with $(+\mathrm{Si})$ or without ( $-\mathrm{Si}) \mathrm{Si}$ and investigated the impacts of $\mathrm{Si}$ supplementation on anti-predator defences of the cotton bollworm, Helicoverpa armigera and plant compensation and trichome production in response to herbivory. Specifically, our objectives were (i) to elucidate the effects of Si on larval growth and feeding and consequently on larval morphological (integument resistance and thickness), behavioural (in the absence and presence of a stimulus), and immune (under immunologically naïve and challenged conditions) defences; and (ii) to determine the impacts of Si supplementation on plant compensation for herbivory and constitutive and induced trichome production. Brachypodium distachyon is a temperate grass with a genetically tractable genome, short life cycle, and phylogenetic connection to important cereal crops (Scholthof et al. 2018). Helicoverpa armigera is a global pest of many high-value agricultural and horticultural crops, costing over US\$7 billion annually due to crop losses and management expenses (Jones et al. 2019). We hypothesized that Si negatively affects larval feeding and growth and thus attenuates the anti-predator defences of larvae by limiting physiological resources.

\section{Materials and methods}

\section{Plants and insect herbivores}

Brachypodium distachyon (accession $\mathrm{Bd} 21-3$ ) seeds were obtained from the French National Research Institute for Agriculture, Food and Environment (INRAE, Paris, France). Seeds were softened by soaking in water for $2 \mathrm{~h}$ and dehusked manually using forceps. Seeds were then sterilised in a solution of $0.9 \% \mathrm{NaOCl}$ and $0.1 \%$ Triton- $\mathrm{X}$ for $30 \mathrm{~min}$ and subsequently washed in water several times. Sterilised seeds were sown in wet perlite in germination trays and kept refrigerated at $4{ }^{\circ} \mathrm{C}$ for 7 days for cold stratification and further grown for 12 days in a naturally lit glasshouse at $22 / 18{ }^{\circ} \mathrm{C}$ day/night temperatures on a cycle of $14 \mathrm{~L}: 10 \mathrm{D}$ and $50 \%( \pm 6 \%)$ relative humidity. Uniform seedlings were transplanted to non-aerated hydroponic vessels, each comprised of two nested disposable plastic cups $(480 \mathrm{ml})$ with a fitted foam disc at the top as per Hall et al. (2020). Foam discs were slot cut to accommodate a seedling in each vessel. 
Cups were filled weekly with $370 \mathrm{ml}$ of freshly prepared nutrient solution with $(+\mathrm{Si})$ or without $(-\mathrm{Si}) \mathrm{Si}$ supplementation as per Hall et al. (2020).

The hydroponic nutrient solution contained $1 \mathrm{mM} \mathrm{KNO}_{3}$, $1 \mathrm{mM} \mathrm{Ca}\left(\mathrm{NO}_{3}\right)_{2} \cdot 4 \mathrm{H}_{2} \mathrm{O}, 1 \mathrm{mM} \mathrm{KH} \mathrm{PO}_{4}, 0.6 \mathrm{mM} \mathrm{MgSO}_{4}$, $0.1 \mathrm{mM} \mathrm{NaCl}, 15 \mu \mathrm{M} \mathrm{H}_{3} \mathrm{BO}_{3}, 0.5 \mu \mathrm{M} \mathrm{MnCl}{ }_{2} \cdot 4 \mathrm{H}_{2} \mathrm{O}$, $0.7 \mu \mathrm{M} \mathrm{ZnSO}_{4} \cdot 7 \mathrm{H}_{2} \mathrm{O}, 0.8 \mu \mathrm{M} \mathrm{Na}_{2} \mathrm{MoO}_{4} \cdot 2 \mathrm{H}_{2} \mathrm{O}, 0.8 \mu \mathrm{M}$ $\mathrm{CuSO}_{4} \cdot 5 \mathrm{H}_{2} \mathrm{O}$, and $0.12 \mathrm{mM} \mathrm{NaFe}(\mathrm{iii})$ EDTA. Non-aerated hydroponics have been used extensively for growing $B$. distachyon (Biru et al. 2021; de la Peña et al. 2019; Johnson et al. 2021b; Jung et al. 2014, 2015; Wang et al. 2019). Given that $B$. distachyon plants have short stature and fresh nutrient solutions were replenished weekly, plant roots received sufficient oxygen in hydroponics for growth and metabolism. Plants $(N=150)$ were grown in the same glasshouse environment, and cups were rotated weekly to avoid any position bias. Helicoverpa armigera (Lepidoptera: Noctuidae) larvae were supplied by CSIRO Agriculture and Food, Narrabri, NSW, Australia and were reared on an artificial diet modified from Teakle and Jensen (1985) before being inoculated onto plants.

\section{Experimental design and treatments}

Liquid potassium silicate $\left(\mathrm{K}_{2} \mathrm{SiO}_{3}\right)\left(21 \% \mathrm{~K}_{2} \mathrm{O}\right.$ and $32 \% \mathrm{SiO}_{2}$, Agsil32, PQ Australia, SA, Australia) was added to the nutrient solution to create the $+\mathrm{Si}$ treatment. The concentration of silicic acid was maintained at $2 \mathrm{mM}\left(\mathrm{SiO}_{2}\right.$ equivalent $)$ in $+\mathrm{Si}$ solution as polymerisation occurs above this concentration (Ma and Yamaji 2006). The added $\mathrm{K}^{+}$ions in the +Si treatment were balanced in the control treatment $(-\mathrm{Si})$ by adding $\mathrm{KCl}$ (Sigma-Aldrich, MO, USA). Both $+\mathrm{Si}$ and $-\mathrm{Si}$ solutions were adjusted to $\mathrm{pH} 5.5$ with $\mathrm{HCl}$. The addition of chloride did not produce any chloride toxicity in plants (Biru et al. 2021; Hall et al. 2020; Johnson et al. 2021b).

Plants were assigned to herbivore treatments (insect or no insect) after being grown hydroponically for five weeks. Eighty plants $(40+\mathrm{Si}$ and $40-\mathrm{Si})$ were randomly exposed to a second instar $H$. armigera larva for seven days. Larvae were starved for $24 \mathrm{~h}$ in Petri dishes before being weighed and placed onto plants. The rest of the plants $(N=70)$ were kept insect-free. All plants were kept caged for seven days in transparent acrylic cylinders (see Johnson et al. (2020) for cage specifications). Larvae were starved for $24 \mathrm{~h}$ in Petri dishes following removal from plants to allow all frass to be expelled and subsequently weighed to estimate the relative growth rates (RGRs) of larvae. Insect RGR is a combined estimate for plant antixenotic (i.e. effects on growth due to starvation) and antibiotic effects and was calculated as larval mass gain relative to initial body mass per unit of time [mass gained (mg)/initial mass (mg)/time (days)] (Massey and Hartley 2009).
We collected larval frass randomly from 40 hydroponic vessels (20 holding + Si plants and 20 holding - Si plants) and matching Petri dishes following second starvation and oven-dried it at $60{ }^{\circ} \mathrm{C}$ for three days before weighing (i.e. as a proxy for leaf consumption by larvae (Murray et al. 2013)). Furthermore, 40 larvae ( 20 fed on + Si plants and 20 fed on -Si plants) were used for assessing behavioural and morphological defences, and the remaining 40 larvae were used for measuring immune defences. Thirty insect-fed plants (15 of each Si treatment) were randomly harvested immediately after insect herbivory, as were 30 insect-free plants (15 of each Si treatment). Plants were oven-dried at $60{ }^{\circ} \mathrm{C}$ for seven days before measuring shoot dry biomass to assess insect damage on $+\mathrm{Si}$ and $-\mathrm{Si}$ plants. Eighty other plants $(N=20$ of each treatment) were grown for an additional two weeks to elucidate the effects of Si supplementation on plant compensation for herbivory and leaf trichome density.

\section{Measurements of larval behavioural and morphological defences}

We measured the escape response of larvae (i.e. flee) in the absence of any stimulus as per Vogelweith et al. (2014). Each larva $(N=20$ of each Si treatment) was placed singly on a gridded plastic sheet $(86 \times 112 \mathrm{~cm})$ and acclimated for $20 \mathrm{~s}$ under a glass jar. Following jar removal, the number of squares crossed by a larva within $60 \mathrm{~s}$ (minimum time to exit the sheet as observed in the preliminary experiment) was recorded. As no stimulus was involved, some larvae (i.e. seven fed on $+\mathrm{Si}$ plants and four fed on $-\mathrm{Si}$ plants) did not make any movements and were omitted from the analysis. Following flee measurements, each larva was placed on white filter paper, acclimated for $30 \mathrm{~s}$ under a glass jar and then gently pinched three times at $20 \mathrm{~s}$ intervals using bracket-placing tweezers at the abdominal end to imitate predator attack (Cornell et al. 1987). The defensive behaviours of larvae were video recorded (Logitech c270 webcam), and three distinct larval behaviours were characterized and logged for each larva: (a) 'headrearing' as characterized by the backward movement of the head and the anterior body portion to the posterior part, (b) 'thrashing' as characterized by the side-to-side swing movement of the head and the anterior body portion, and (c) 'regurgitating' on filter paper (Cornell et al. 1987).

We further measured larval integument resistance and integument thickness following the protocol of Vogelweith et al. (2014) with minor modifications. Larvae were placed at $-20{ }^{\circ} \mathrm{C}$ for $20 \mathrm{~min}$ and then thawed for $10 \mathrm{~min}$ before starting measurements. Integument resistance was measured using a drill press equipped with a hypodermic needle (Terumo, $0.5 \times 16 \mathrm{~mm})$. A precision scale $( \pm 0.1 \mathrm{mg})$ was positioned on the drill press table, and each larva mounted on a cardboard sheet was placed over the scale. The needle was 
slowly lowered down by rotating the lever until it breached the dorsal integument. The scale reading $(\mathrm{mg})$ when the needle breached the integument was recorded. Two measurements were taken from each larva, one on the thoracic region and another on the abdomen, and the average value was counted. Larvae were further dissected, and all internal organs and fat bodies were removed before measuring integument thickness using a thickness gauge (Teclock SM-112, Japan, precision $\pm 0.01 \mathrm{~mm}$ ) (Iltis et al. 2018).

\section{Measurements of larval immune defences}

We measured the innate immunity of larvae (10 larvae fed on $+\mathrm{Si}$ plants and 10 larvae fed on $-\mathrm{Si}$ plants) in terms of haemocyte density, phenoloxidase (PO) activity, total-PO activity (combined estimate of $\mathrm{PO}$ and its precursor, prophenoloxidase), and lysozyme-like enzyme activity in the haemolymph. For this, immunologically naïve (unchallenged) larvae were chilled on ice for $20 \mathrm{~min}$, a proleg was removed from each larva using a sterile micro scissor, and $3 \mu \mathrm{l}$ of haemolymph was collected immediately using a sterile micropipette. Of this, $2 \mu \mathrm{l}$ was flushed into a prechilled microcentrifuge tube containing $20 \mu \mathrm{l}$ of cold phosphate-buffered saline (PBS, $\mathrm{pH}$ 7.4). Ten microliters of this haemolymph-PBS mixture was spread immediately over a Neubauer Improved Haemocytometer, and haemocytes were counted under a phase-contrast microscope at $400 \times$ magnification (Axio Vert.A1, Zeiss, Australia). We measured the total haemocyte density and the density of individual haemocytes, classified according to Vogelweith et al. (2016) and Ribeiro and Brehélin (2006), into prohaemocytes, granulocytes, plasmatocytes, spherulocytes, and oenocytoids.

The rest of the haemolymph-PBS mixtures were stored at $-20{ }^{\circ} \mathrm{C}$ for the later measurements of PO and total-PO activities following the protocol of Vogelweith et al. (2011). Briefly, samples ( $N=10$ of each Si treatment) were thawed slowly on ice and centrifuged $\left(3000 \mathrm{~g}, 4^{\circ} \mathrm{C}\right)$ for $15 \mathrm{~min}$. Five microliters of supernatant from each sample was transferred to a microplate well containing $20 \mu \mathrm{l}$ of PBS with either $140 \mu \mathrm{l}$ of distilled water for measuring PO activity or $140 \mu \mathrm{l}$ of chymotrypsin solution (Sigma-Aldrich, $0.98 \mathrm{mg} / 14 \mathrm{ml}$ of distilled water) for measuring total-PO activity. Finally, $20 \mu \mathrm{l}$ of L-DOPA solution (Sigma-Aldrich, $8 \mathrm{mg} / 2 \mathrm{ml}$ of distilled water) was added as a substrate to each microplate well, and the absorbance readings were taken for samples and negative controls at $490 \mathrm{~nm}$ using a microplate reader (CLARIOstar Plus, BMG Labtech) for $40 \mathrm{~min}$ at $60 \mathrm{~s}$ intervals. The enzyme activity was calculated from the slope of the reaction curve (i.e. changes in optical density per min) at the linear phase and is reported as the activity per microliter of pure haemolymph.

An additional $1 \mu \mathrm{l}$ of pure haemolymph was flushed into a pre-chilled microcentrifuge tube containing $10 \mu \mathrm{l}$ of reaction buffer (pH 6.24, Sigma-Aldrich) and stored at $-20{ }^{\circ} \mathrm{C}$ for the subsequent measurements of lysozyme-like activity. Lysozyme-like activity was measured by a turbidity assay using Micrococcus lysodeikticus (Sigma-Aldrich) as a substrate following the method modified from Adamo et al. (2016). In short, $10 \mu \mathrm{l}$ of haemolymph-reaction buffer mixture from each sample was transferred to a microplate well containing $180 \mu \mathrm{l}$ of a suspension of M. lysodeikticus cells $(1 \mathrm{mg} / 10 \mathrm{ml})$ in reaction buffer (pH 6.24, Sigma-Aldrich). Lysozyme standards (Sigma-Aldrich) within the linear range of assays were run concurrently as positive controls along with the test samples and negative controls, and the kinetic decrease in absorbance was recorded using a microplate reader (CLARIOstar Plus, BMG Labtech) at $450 \mathrm{~nm}$ wavelength for $10 \mathrm{~min}$ at $50 \mathrm{~s}$ intervals. Lysozyme-like activities are presented in units, where one unit represents a 0.001 change in optical density per minute.

Furthermore, we measured the melanisation responses of larvae (10 larvae fed on + Si plants and 10 larvae fed on $-\mathrm{Si}$ plants) when immunologically challenged simulating solitary endoparasitoid attack (Moreno-García et al. 2013). For this, a nylon monofilament $(0.2 \mathrm{~mm}$ diameter) was implanted $2 \mathrm{~mm}$ deep in the haemocoel through the dorsal abdominal part of each larva according to Gherlenda et al. (2016). After $24 \mathrm{~h}$, we collected $3 \mu \mathrm{l}$ of haemolymph from each larva and measured haemolymph PO, total-PO, and lysozyme-like activities as per the procedures described previously. The nylon implants were removed and photographed using a stereo microscope (Olympus, SZ61) mounted camera (Infinity 1 , Teledyne Lumenera) along with a control filament (i.e. not implanted in the haemocoel). The photos were processed in ImageJ (National Institutes of Health, Maryland; Version 1.52 ) and the mean grey values were estimated on a scale of 0 (light) to 255 (dark). The melanisation scores were calculated using the formula: 1 - (mean grey value of the treatment filament/mean grey value of the control filament) (Garvey et al. 2021).

\section{Measurements of leaf trichome density, plant compensation, and Si concentrations}

We measured the density of non-glandular trichomes (or macrohairs) on leaves of all 80 plants $(N=20$ of each treatment) grown for an additional two weeks following herbivory or no herbivory. Non-glandular trichomes can defend plants against insect herbivores, often more effectively than plant secondary metabolites (Carmona et al. 2011), and herbivory can induce increased trichome density on newly emerged leaves (Dalin et al. 2008). We sampled the newly emerged, fully expanded leaves from plants and counted trichomes on abaxial and adaxial surfaces $(4 \mathrm{~mm} \times 4 \mathrm{~mm}$ area in the middle) under a stereo microscope (Olympus, 
SZX10). Plants were subsequently harvested and ovendried at $60{ }^{\circ} \mathrm{C}$ for 7 days, and shoot and root biomass was recorded.

Plant compensation is defined as the process by which plants mitigate or nullify the damage caused by herbivory (Bardner and Fletcher 1974), and it can be assessed by comparing the biomass of insect-fed plants with insect-free control plants (Arab and Trigo 2011; Belsky 1986; Gavloski and Lamb 2000). We therefore harvested plants at two-time points for assessing plant compensation and compared at each time point the dry biomass of insect-fed-Si plants with insect-free - Si plants and the dry biomass of insect-fed $+\mathrm{Si}$ plants with insect-free + Si plants. The first group of plants was harvested immediately after herbivory (as mentioned in the experimental design) to measure biomass losses of $-\mathrm{Si}$ and + Si plants due to insect attack, and the second group of plants was harvested two weeks after herbivory to assess compensation of $-\mathrm{Si}$ and $+\mathrm{Si}$ plants for herbivory (Arab and Trigo 2011). Furthermore, the second group of plants was used for Si quantification. The concentrations of total $\mathrm{Si}(\%$ dry mass) in the leaves and roots of $40+\mathrm{Si}$ plants $(20$ insect-fed plants and 20 insect-free plants) were measured. For this, ca. $80 \mathrm{mg}$ of oven-dried, ball-milled samples was analysed using an X-ray fluorescence spectrometer (Epsilon $3^{\mathrm{x}}$; PANalytical, EA Almelo, The Netherlands) according to Reidinger et al. (2012). Measurements were standardized using certified plant material of known Si concentration (NCS ZC73018 Citrus leaves, China National Institute for Iron and Steel).

\section{Statistical analysis}

All data were analysed in the statistical software environment R, version 3.6.1 (R Core Team 2019). The distributions of dependent and independent variable datasets were compared using quantile-quantile plots, and homogeneity of variance was assessed using 'residuals versus fits' plots. Larval frass and morphological and behavioural defence parameters were analysed using Wilcoxon's rank-sum tests as the assumptions of normality of residuals or homoscedasticity were violated (Fig. S1). Larval RGR, haemocyte density, PO, total-PO, lysozyme-like activity, and leaf and root $\mathrm{Si}$ concentrations were analysed using Student's $t$-tests. Haemolymph PO activity was compared with total PO for each Si treatment under similar immunological conditions using Student's $t$-tests. The effect of Si on larval integument resistance and $\mathrm{PO}$ activity was analysed using multiple linear regressions. The relationships between larval integument resistance and weight gain and final weight were explored using Spearman's correlations. Leaf trichome density and shoot and root biomass were analysed using two-way analysis of variance (ANOVA) tests, considering $\mathrm{Si}$ and insect herbivory as fixed factors. When the main or interaction effects of factors were significant in ANOVAs, differences between group means were determined by Tukey's HSD tests.

\section{Results}

\section{Insect growth, feeding, and anti-predator defences}

Larval RGR and frass production were significantly lower $(-300 \%$ and $-85 \%$, respectively) when feeding on $+\mathrm{Si}$ plants compared to when feeding on -Si plants (Fig. 1a, b; Table 1). However, none of the larval defensive behaviours (flee, headrear, thrash, and regurgitation) were affected by Si (Table S1). Larvae fed on +Si plants had significantly lower integument resistance than larvae fed on -Si plants (Fig. 2a; Table 1) despite no significant difference in integument thickness (Fig. 2b; Table 1). Integument resistance was strongly and positively correlated with larval weight gain $(N=40, \rho=0.83, p<0.001)$ and final weight $(N=40$, $\rho=0.98, p<0.001$ ) (Fig. S2). Multiple linear regression analysis showed that $\mathrm{Si}$ had a significant effect on integument resistance after adjusting for the effect of larval weight gain (Table 3). However, Si had no significant effect on integument resistance when the effect of larval final weight was controlled (Table 3).

The density of individual and total haemocytes in the haemolymph was unaffected by Si (Fig. S3; Table S3). Larvae fed on +Si plants had significantly higher PO and total$\mathrm{PO}$ activities in the haemolymph compared to larvae fed on -Si plants under both immunologically naïve (unchallenged) (71\% and $86 \%$ increase in $\mathrm{PO}$ and total PO, respectively) and challenged conditions (33\% increase in both PO and total PO) (Fig. 3a, b; Table 1). Accordingly, Si had a significant effect on haemolymph PO activity after controlling for the effect of larval weight gain or final weight (Table 3). There were no significant differences between haemolymph $\mathrm{PO}$ and total $\mathrm{PO}$ activities in larvae fed on $-\mathrm{Si}$ or $+\mathrm{Si}$ plants under similar
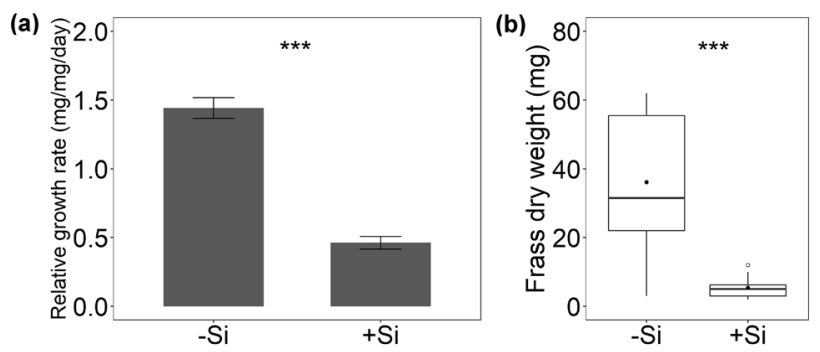

Fig. 1 a Larval relative growth rate $(\mathrm{mg} / \mathrm{mg} /$ day $)$ and b Frass dry weight $(\mathrm{mg})$ on $-\mathrm{Si}$ and $+\mathrm{Si}$ plants. Mean \pm SE shown $(N=40)$. Group means were compared using Student's $t$-tests. Asterisks indicate the level of statistical significance $(* * * p<0.001)$ at $95 \%$ confidence intervals 
Table 1 Summary output of Student's $t$-tests and Wilcoxon's ranksum tests for comparing treatment $(-\mathrm{Si}$ and $+\mathrm{Si})$ means. Statistically significant effects $(p<0.05)$ are indicated in bold

\begin{tabular}{|c|c|c|c|c|}
\hline \multirow[t]{2}{*}{ Response variable } & \multirow[t]{2}{*}{ Fig } & \multicolumn{3}{|c|}{ Statistical analysis } \\
\hline & & $d f$ & $\begin{array}{l}\text { Test statistic } \\
\left(t \mathrm{a} / W^{\mathrm{b}}\right)\end{array}$ & $p$ value \\
\hline Larval RGR ${ }^{\text {a }}$ & 1a & 78 & 11.18 & $<0.001$ \\
\hline Frass dry weight ${ }^{b}$ & $1 \mathrm{~b}$ & - & 381.5 & $<0.001$ \\
\hline \multicolumn{5}{|c|}{ Larval morphological defences ${ }^{b}$} \\
\hline Integument resistance & $2 \mathrm{a}$ & - & 385.5 & $<0.001$ \\
\hline Integument thickness & $2 \mathrm{~b}$ & - & 227.5 & 0.442 \\
\hline \multicolumn{5}{|c|}{ Immune defences of nä̈ve (unchallenged) larvae ${ }^{a}$} \\
\hline PO activity & $3 \mathrm{a}$ & 18 & -2.94 & 0.009 \\
\hline Total-PO activity & $3 b$ & 18 & -2.74 & 0.014 \\
\hline \multicolumn{5}{|c|}{ Immune defences of challenged larvae ${ }^{a}$} \\
\hline PO activity & $3 \mathrm{a}$ & 18 & -2.28 & $\mathbf{0 . 0 3 5}$ \\
\hline Total-PO activity & $3 b$ & 18 & -2.82 & 0.011 \\
\hline Melanisation score & 4 & 18 & 1.27 & 0.222 \\
\hline \multicolumn{5}{|c|}{ Si concentrations in plants ${ }^{a}$} \\
\hline Leaf $\mathrm{Si}$ & 7 & 38 & -4.85 & $<0.001$ \\
\hline Root Si & 7 & 38 & -0.06 & 0.949 \\
\hline
\end{tabular}

aAnalysed using a Student's $t$-test

${ }^{\mathrm{b}}$ Analysed using a Wilcoxon's rank-sum test (a)

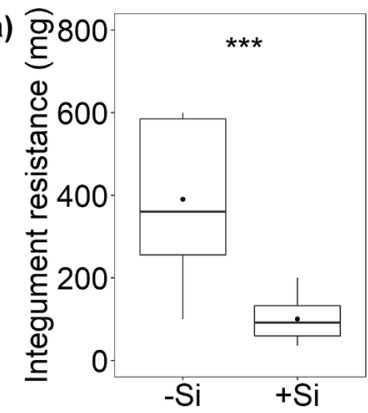

(b)

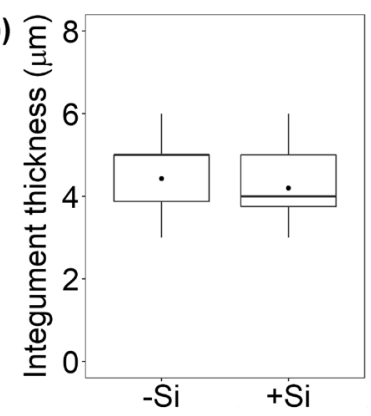

Fig. 2 a Integument resistance $(\mathrm{mg})$ and $\mathbf{b}$ Integument thickness $(\mu \mathrm{m})$ of larvae fed on $-\mathrm{Si}$ and $+\mathrm{Si}$ plants. The median and interquartile range $(N=20)$ are shown along with the mean (black circle). Differences between treatments were determined using Wilcoxon's ranksum tests. Asterisks indicate the level of statistical significance at a $95 \%$ confidence interval $(* * * p<0.001)$

immunological conditions (Table S2). However, the melanisation responses of larvae fed on $+\mathrm{Si}$ or $-\mathrm{Si}$ plants were statistically similar (Fig. 4; Table 1). Lysozyme-like activity in the haemolymph was unaffected by $\mathrm{Si}$, regardless of immunity challenge (Fig. S4; Table S3).

\section{Leaf trichomes, plant compensatory growth, and silicon concentrations}

Silicon in interaction with insect herbivory significantly affected leaf trichome density, whereby $+\mathrm{Si}$ plants had higher $(+51 \%)$ trichome density on abaxial leaf surfaces than - Si plants in the absence of insect herbivory (Fig. 5a; Table 2). However, trichome density on abaxial leaf surfaces of - Si plants increased by $46 \%$ following herbivory and became statistically similar to that of $+\mathrm{Si}$ plants. Likewise, trichome density on adaxial leaf surfaces of $-\mathrm{Si}$ plants significantly increased $(+62 \%)$ following herbivory (Fig. 5b; Table 2). In terms of plant biomass, insect herbivory significantly reduced the shoot biomass of both $-\mathrm{Si}$ and $+\mathrm{Si}$ plants $(-16 \%$ and $-14 \%$, respectively) harvested immediately after herbivory (Fig S5; Table S4). There was a significant interaction between $\mathrm{Si}$ and herbivory on the shoot biomass of plants harvested two weeks afterwards, whereby insect-fed + Si plants produced similar shoot biomass to insect-free + Si plants (Fig. 6a; Table 2), indicating exact plant compensation with the provision of Si. However, root biomass was unaffected by Si or herbivory (Fig. 6b; Table 2). In addition, insect herbivory significantly increased leaf $\mathrm{Si}$ accumulation by ca. $29 \%$ but had no effect on root $\mathrm{Si}$ concentrations (Fig. 7; Table 1).

\section{Discussion}

We report for the first time, to our knowledge, how Si supplementation of plants impacts the morphological and behavioural defences of an insect herbivore. Silicon reduced larval RGRs and feeding, thereby lowering integument resistance which was associated with compensatory production of immunity proteins in the haemolymph. Moreover, Si supply enhanced constitutive trichome production on leaves and augmented plant compensation for herbivory whereas insect herbivory induced trichome production on plants that had no access to Si. (Table 3 ).

\section{Silicon weakened larval morphological defence but did not affect defensive behaviours}

Larvae fed less on + Si plants (i.e. as evident from the lower levels of frass production) and displayed retarded growth rates, which is in line with the existing literature on the effects of Si against chewing herbivores, including folivores (Biru et al. 2021; Islam et al. 2020; Johnson et al. 2020), borers (Kvedaras et al. 2009; Nikpay et al. 2015) and root feeders (Frew et al. 2017). The threefold decrease in larval growth rates observed here due to malnutrition could potentially impact biocontrol by natural enemies. For example, Remmel et al. (2011) estimated that a twofold rise in the 


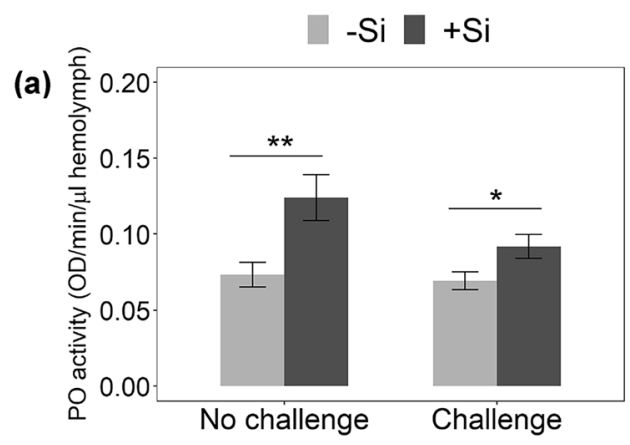

Fig. 3 The activity of a Phenoloxidase (PO) and b Total-PO per microliter of larval haemolymph. Larvae were either challenged by implanting a nylon filament or kept unchallenged following feeding

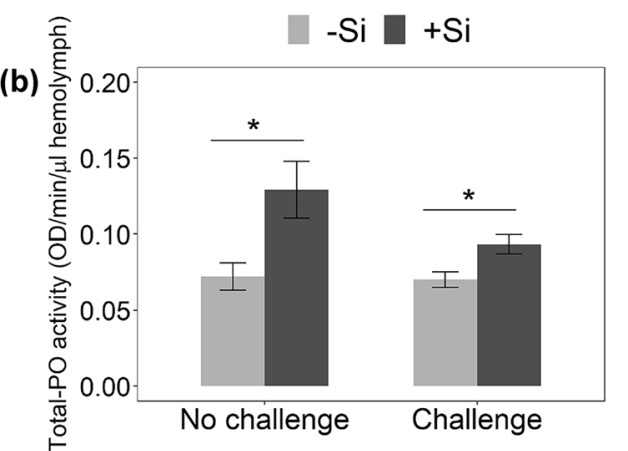

on $-\mathrm{Si}$ or $+\mathrm{Si}$ plants. Mean $\pm \mathrm{SE}$ shown $(N=10)$. Group means were compared using Student's $t$-tests. Asterisks indicate the level of statistical significance $\left(* p<0.05,{ }^{* *} p<0.01\right)$ at $95 \%$ confidence intervals

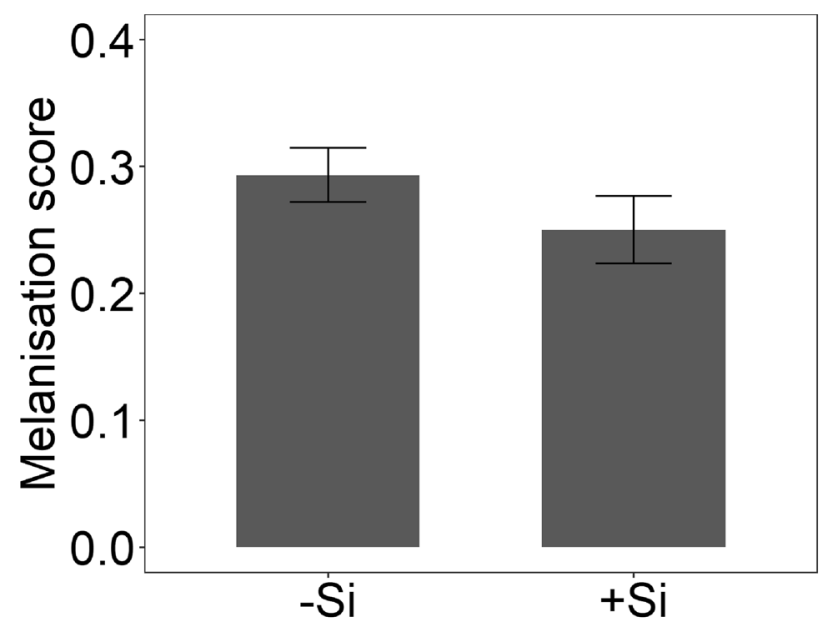

Fig. 4 Melanisation responses of larvae fed on $-\mathrm{Si}$ and $+\mathrm{Si}$ plants. Mean \pm SE shown $(N=10)$. Group means were compared using a Student's $t$-test linear size of folivorous insect larvae increases avian predation rates by 3.6 -fold while reducing arthropod predation rates by 4.9 -fold.

We found a strong positive correlation between larval final weight and integument resistance $(N=40, \rho=0.98$, $p<0.001)$. In accordance with this, Iltis et al. (2018) reported a positive correlation between larval body size and integument resistance of the lepidopteran grape pest, Lobesia botrana, despite no changes in integument thickness. Although it is not evident how larger larvae showed higher integument resistance despite similar integument thickness, we speculate that there might be some variations in the integument ultrastructures of larvae fed on -Si plants compared to larvae fed on + Si plants, including the extent of sclerotization and tanning. This finding suggests that feeding on $+\mathrm{Si}$ plants could make larvae more vulnerable to parasitoid attack, as parasitoid oviposition is often more successful in smaller larvae with lower

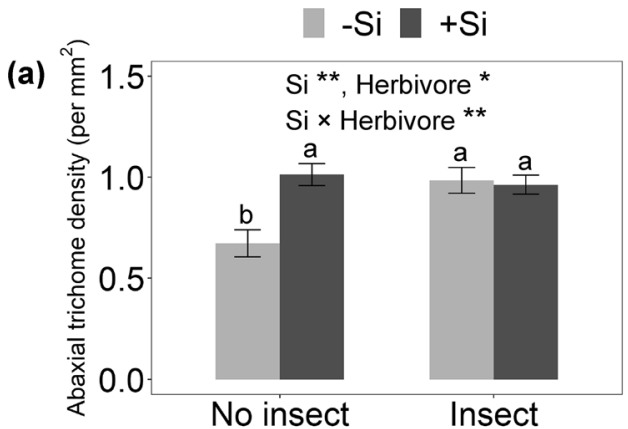

Fig. 5 Impacts of Si and herbivory on the density of trichomes (number per $\mathrm{mm}^{2}$ ) on a Abaxial and $\mathbf{b}$ Adaxial leaf surfaces. Mean $\pm \mathrm{SE}$ shown $(N=20)$. Data were analysed using two-way ANOVA tests and subsequently using Tukey's HSD tests. Asterisks indicate the level of

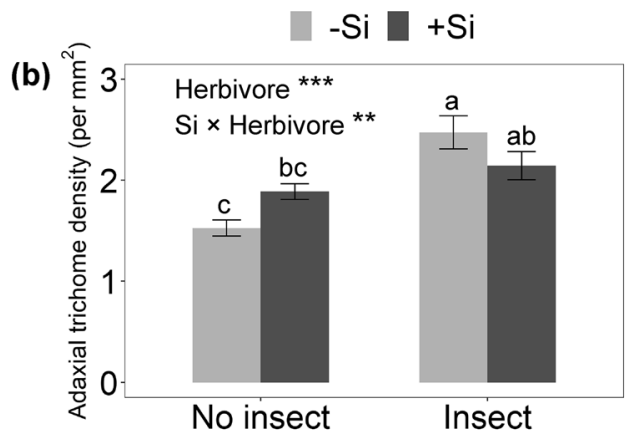

statistical significance $(* p<0.05, * * p<0.01$, *** $p<0.001)$. Different lowercase letters indicate significant differences between means at $95 \%$ confidence intervals 
Table 2 Summary output of two-way ANOVA for the effects of $\mathrm{Si}$ and insect herbivory on leaf trichome density and plant biomass. Statistically significant effects $(p<0.05)$ are indicated in bold

\begin{tabular}{|c|c|c|c|c|c|c|c|c|}
\hline \multirow[t]{2}{*}{ Response variable } & \multirow[t]{2}{*}{ Fig } & \multirow[t]{2}{*}{$d f$} & \multicolumn{2}{|l|}{$\mathrm{Si}$} & \multicolumn{2}{|c|}{ Herbivore } & \multicolumn{2}{|c|}{ Si $\times$ Herbivore } \\
\hline & & & $F$ & $p$ value & $F$ & $p$ value & $F$ & $p$ value \\
\hline Abaxial trichome density & $5 \mathrm{a}$ & 1,76 & 7.49 & 0.008 & 5.08 & 0.027 & 9.69 & 0.003 \\
\hline Adaxial trichome density & $5 b$ & 1,76 & 0.02 & 0.888 & 24.62 & $<0.001$ & 8.11 & 0.006 \\
\hline Shoot biomass & $6 a$ & 1,76 & 63.13 & $<0.001$ & 5.00 & 0.028 & 13.42 & $<0.001$ \\
\hline Root biomass & $6 \mathrm{~b}$ & 1,76 & 0.001 & 0.982 & 0.95 & 0.333 & 0.01 & 0.908 \\
\hline
\end{tabular}

\section{$-\mathrm{Si}+\mathrm{Si}$}

(a)

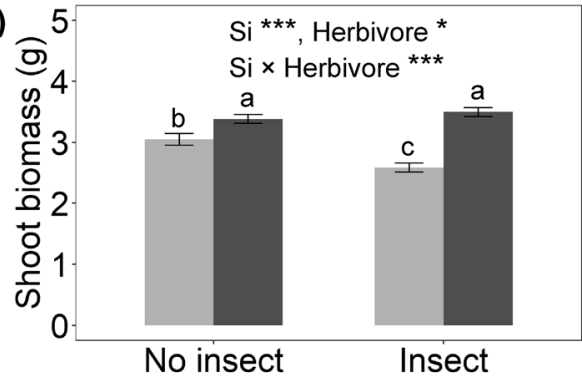

Fig. 6 Impacts of Si and herbivory on dry a Shoot biomass and b Root biomass of plants. Mean \pm SE shown $(N=20)$. Data were analysed using two-way ANOVA tests and further using Tukey's HSD

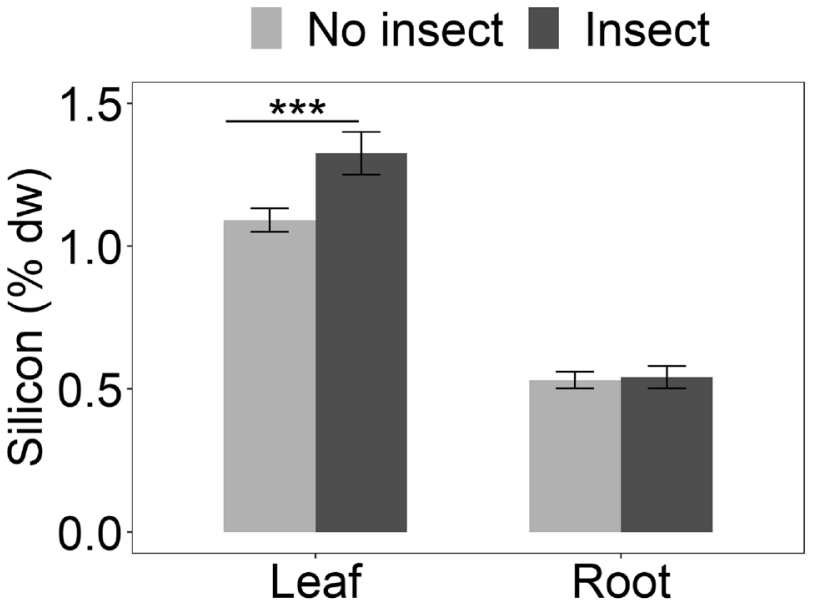

Fig. 7 Concentrations (\% dry weight) of total $\mathrm{Si}$ in the leaves and roots of $+\mathrm{Si}$ plants in the absence or presence of insect herbivory. Mean \pm SE shown $(N=20)$. Group means were compared using Student's $t$-tests. Asterisks indicate the level of statistical significance at a $95 \%$ confidence interval $(* * * p<0.001)$

integument resistance (Beckage and Riddiford 1978; Gross 1993). We observed consistent defensive behaviours of $H$. armigera larvae, irrespective of lower leaf consumption and growth rates. This result concurs with the findings of Zhou et al. (2017), who found that evasive (escape) and aggressive (thrashing and dropping) behaviours of the oriental armyworm, Mythimna separata, were unaffected by body size and weight.

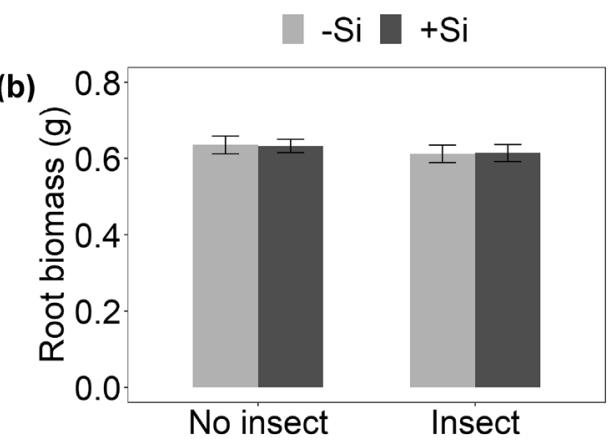

tests. Asterisks indicate the level of statistical significance $(* p<0.05$, $* * p<0.01, * * * \quad p<0.001)$. Different lowercase letters indicate significant differences between means at $95 \%$ confidence intervals

\section{Interactions between larval morphological and immune defences}

Our results indicate a potential trade-off between insect morphological and immune defences; larvae fed on $+\mathrm{Si}$ plants had lower integument resistance but higher haemolymph PO and total-PO activities. Such trade-offs between antipredator defensive traits have been demonstrated in other lepidopteran (Vogelweith et al. 2014) and hymenopteran (Boevé and Schaffner 2003) larvae, including trade-offs caused by variations in larval diet (Vogelweith et al. 2011). For instance, in several sawfly species, a lower integument resistance and propensity for bleeding have been linked to a higher haemolymph deterrence against predators such as ants and wasps (Boevé and Schaffner 2003). Our results differ from the previous study by Frew et al. (2017), who found no effects of Si supplementation of sugarcane on PO activity in the root-feeding grub, Dermolepida albohirtum.

Even though the underlying mechanisms of how $\mathrm{Si}$ enhanced PO activity in the haemolymph are not clear, previous research has shown that consumption of plant toxins (e.g. nicotine) or starvation could be immunotherapeutic for insects and could enhance PO activity (Garvey et al. 2021; Yang et al. 2007). We suggest that Si accumulation in plants forced larvae into starvation and consumption of silicified tissues and trichomes may have caused larval gut damage and exerted physiological stress on them, contributing to higher haemolymph PO activities. This high level of PO may impose fitness costs on larvae, as the production and 


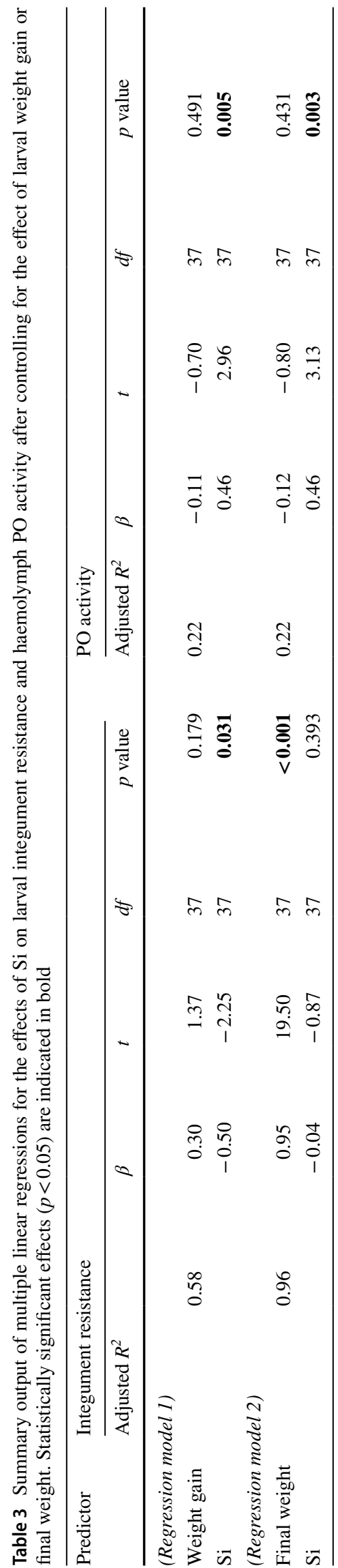

maintenance of PO is very costly (González-Santoyo and Córdoba-Aguilar 2012) and resource allocation to PO could constrain resources for other physiological functions, including larval development (Cotter et al. 2008) and the expression of sexual traits (Siva-Jothy 2000).

\section{High PO activity did not enhance melanisation}

We found no differences between haemolymph PO and total-PO activities in larvae under similar immunological conditions (challenge or no challenge), which could be because naturally activated PO denotes total-PO activity in the haemolymph of larvae (Vogelweith et al. 2011). Thus, the addition of chymotrypsin as an artificial PO activator did not enhance total-PO activity. Notably, high PO activity in the haemolymph of larvae fed on $+\mathrm{Si}$ plants did not enhance their melanisation responses when larvae were immunologically challenged. In lepidopteran larvae, circulating haemocytes, namely, oenocytoids, produce prophenoloxidase (proPO) zymogen, which is further activated into PO following proteolytic cleavage (Kanost and Gorman 2008). Although high PO activity often positively impacts encapsulation and melanisation (González-Santoyo and Córdoba-Aguilar 2012; Shiao et al. 2001), some previous studies have found no such positive associations (Piñera et al. 2013; Wilson-Rich et al. 2008). Since PO functions against pathogens and parasitoids via melanogenesis (i.e. a process whereby $\mathrm{PO}$ oxidises phenols to quinones, which further polymerise to melanin) (Eleftherianos and Revenis 2011), our finding suggests that high PO activity does not necessarily imply high immune defences in larvae; rather, it could signify larval physiological stress (González-Santoyo and Córdoba-Aguilar 2012).

The possible explanations for similar melanisation responses in larvae are twofold. First, melanisation depends on both PO activity and haemocyte density, as invaders need to be first coated (i.e. encapsulation) by adhesive haemocyte cells (Lavine and Strand 2002). Given that the density of haemocytes in larvae fed on $+\mathrm{Si}$ or $-\mathrm{Si}$ plants was similar, larvae may have produced an identical encapsulation of the nylon implants. Second, both the activation of $\mathrm{PO}$ and the production of melanin (a nitrogen-rich compound) require substantial investments of nitrogen (González-Santoyo and Córdoba-Aguilar 2012). Hence, high PO activity in the haemolymph can limit nitrogen for melanogenesis in larvae when feeding on $+\mathrm{Si}$ plants, especially considering the fact that $\mathrm{Si}$ and nitrogen accumulation in plants can interact antagonistically (Wu et al. 2017).

\section{Post-attack plant defences}

We found that $\mathrm{Si}$ increased constitutive trichome density on leaves, which substantiates previous studies on grasses (Biru 
et al. 2021; Johnson et al. 2021a) and other crops (Acevedo et al. 2021). Interestingly, herbivory induced trichome production only on $-\mathrm{Si}$ plants because $+\mathrm{Si}$ plants were already better defended with constitutively-produced silicified trichomes, which were found to be essential for defence against chewing herbivores in rice (Andama et al. 2020). We suggest that investment in induced trichome defence by $-\mathrm{Si}$ plants might compromise, in part, their capacity for compensatory growth, as there could be a potential trade-off between plant growth and defence (Herms and Mattson 1992; but see Koricheva 2002). Conversely, with the provision of $\mathrm{Si}$, insect-fed plants produced similar biomass to insect-free plants within two weeks of the recovery period, despite initial biomass losses, substantiating the previous finding that Si can support plant compensatory growth (Johnson et al. 2019).

\section{Conclusions}

Our study establishes that Si supplementation of plants can affect the anti-predator defences of insect herbivores. Moreover, Si supply can increase constitutive trichome production on leaves and augment plant compensation for herbivory. We found a potential trade-off between larval morphological and immune defences when fed on siliceous plants; a lower integument resistance was associated with higher PO and total-PO activities in the haemolymph, although it did not enhance the melanisation response of larvae when challenged. We presume that the lower integument resistance of larvae could enhance their vulnerability to some natural enemies and that high PO activity could impose physiological costs, potentially impeding other physiological functions. However, reduced anti-predator defences of larvae do not necessarily guarantee increased biological control by natural enemies, and further research is needed to understand how changes in anti-predator defences of herbivorous insects under Si supplementation impact their susceptibility to natural enemies in realistic settings. Nonetheless, our study provides the first evidence for the plant-mediated effects of $\mathrm{Si}$ on anti-predator defences of an insect herbivore and presents a framework for studying the impacts of Si on natural enemies of herbivores via changes in anti-predator defences of host insects.

\section{Authors contribution}

TI and SNJ conceived and designed the study. TI conducted experimental work, collected and analysed data, and drafted the manuscript. SNJ and BDM supervised TI. All authors critically revised the draft and approved the final manuscript for publication.
Supplementary Information The online version contains supplementary material available at https://doi.org/10.1007/s10340-022-01478-4.

Acknowledgements TI is the holder of a scholarship as part of an Australian Research Council Future Fellowship (FT170100342) awarded to SNJ. We would like to thank Mr Burhan Amiji and Dr Craig Barton for their technical supports to the work. We also thank Ximena CibilsStewart, Rocky Putra, Fikadu N. Biru and Jamie M. Waterman for their helpful edits to the manuscript.

Funding Open Access funding enabled and organized by CAUL and its Member Institutions.

Data availability The data that support the findings of this study are available in the figshare repository, https://doi.org/10.6084/m9.figsh are.15085815.v1

\section{Declarations}

Conflict of interest The authors declare that there are no conflicts of interest.

Open Access This article is licensed under a Creative Commons Attribution 4.0 International License, which permits use, sharing, adaptation, distribution and reproduction in any medium or format, as long as you give appropriate credit to the original author(s) and the source, provide a link to the Creative Commons licence, and indicate if changes were made. The images or other third party material in this article are included in the article's Creative Commons licence, unless indicated otherwise in a credit line to the material. If material is not included in the article's Creative Commons licence and your intended use is not permitted by statutory regulation or exceeds the permitted use, you will need to obtain permission directly from the copyright holder. To view a copy of this licence, visit http://creativecommons.org/licenses/by/4.0/.

\section{References}

Acevedo FE, Peiffer M, Ray S, Tan CW, Felton GW (2021) Siliconmediated enhancement of herbivore resistance in agricultural crops. Front Plant Sci 12:631824. https://doi.org/10.3389/fpls. 2021.631824

Adamo SA, Davies G, Easy R, Kovalko I, Turnbull KF (2016) Reconfiguration of the immune system network during food limitation in the caterpillar Manduca sexta. J Exp Biol 219:706-718. https:// doi.org/10.1242/jeb.132936

Andama JB, Mujiono K, Hojo Y, Shinya T, Galis I (2020) Nonglandular silicified trichomes are essential for rice defense against chewing herbivores. Plant Cell Environ 43:2019-2032. https:// doi.org/10.1111/pce. 13775

Arab A, Trigo JR (2011) Host plant invests in growth rather than chemical defense when attacked by a specialist herbivore. J Chem Ecol 37:492-495. https://doi.org/10.1007/s10886-011-9955-y

Bardner R, Fletcher KE (1974) Insect infestations and their effects on the growth and yield of field crops: a review. Bull Entomol Res 64:141-160. https://doi.org/10.1017/S0007485300027061

Beckage NE, Riddiford LM (1978) Developmental interactions between the tobacco hornworm Manduca sexta and its braconid parasite Apanteles congregatus. Entomol Exp Appl 23:139-151. https://doi.org/10.1111/j.1570-7458.1978.tb03016.x

Belsky AJ (1986) Does herbivory benefit plants? a review of the evidence. Am Nat 127:870-892. https://doi.org/10.1086/284531 
Bernays EA (1997) Feeding by lepidopteran larvae is dangerous. Ecol Entomol 22:121-123. https://doi.org/10.1046/j.1365-2311.1997. 00042.x

Biru FN, Islam T, Cibils-Stewart X, Cazzonelli CI, Elbaum R, Johnson SN (2021) Anti-herbivore silicon defences in a model grass are greatest under Miocene levels of atmospheric $\mathrm{CO}_{2}$. Global Change Biol 27:2959-2969. https://doi.org/10.1111/gcb.15619

Boevé J-L, Schaffner U (2003) Why does the larval integument of some sawfly species disrupt so easily? The harmful haemolymph hypothesis. Oecologia 134:104-111. https://doi.org/10.1007/ s00442-002-1092-4

Carmona D, Lajeunesse MJ, Johnson MTJ (2011) Plant traits that predict resistance to herbivores. Funct Ecol 25:358-367. https://doi. org/10.1111/j.1365-2435.2010.01794.x

Cornell JC, Stamp NE, Bowers MD (1987) Developmental change in aggregation, defense and escape behavior of buckmoth caterpillars, Hemileuca lucina (Saturniidae). Behav Ecol Sociobiol 20:383-388. https://doi.org/10.1007/BF00302980

Cotter SC, Myatt JP, Benskin CM, Wilson K (2008) Selection for cuticular melanism reveals immune function and life-history trade-offs in Spodoptera littoralis. J Evol Biol 21:1744-1754. https://doi. org/10.1111/j.1420-9101.2008.01587.x

Dalin P, Ågren J, Björkman C, Huttunen P, Kärkkäinen K (2008) Leaf trichome formation and plant resistance to herbivory. In: Schaller A (ed) Induced Plant Resistance to Herbivory. Springer, Dordrecht, pp 89-105

de la Peña M, González-Moro MB, Marino D (2019) Providing carbon skeletons to sustain amide synthesis in roots underlines the suitability of Brachypodium distachyon for the study of ammonium stress in cereals. AoB Plants 11(3):plz029. https://doi.org/10. 1093/aobpla/plz029

Diamond SE, Kingsolver JG (2011) Host plant quality, selection and trade-offs shape the immunity of Manduca sexta. Proc R Soc B 278:289-297. https://doi.org/10.1098/rspb.2010.1137

Eleftherianos I, Revenis C (2011) Role and importance of phenoloxidase in insect hemostasis. J Innate Immun 3:28-33. https://doi. org/10.1159/000321931

Forkner RE, Hunter MD (2000) What goes up must come down? Nutrient addition and predation pressure on oak herbivores. Ecology 81:1588-1600. https://doi.org/10.1890/0012-9658(2000) 081[1588:WGUMCD]2.0.CO;2

Frew A, Powell JR, Hiltpold I, Allsopp PG, Sallam N, Johnson SN (2017) Host plant colonisation by arbuscular mycorrhizal fungi stimulates immune function whereas high root silicon concentrations diminish growth in a soil-dwelling herbivore. Soil Biol Biochem 112:117-126. https://doi.org/10.1016/j.soilbio.2017.05.008

Garvey M, Bredlau J, Kester K, Creighton C, Kaplan I (2021) Toxin or medication? Immunotherapeutic effects of nicotine on a specialist caterpillar. Funct Ecol 35:614-626. https://doi.org/10.1111/ 1365-2435.13743

Gatehouse JA (2002) Plant resistance towards insect herbivores: a dynamic interaction. New Phytol 156:145-169. https://doi.org/ 10.1046/j.1469-8137.2002.00519.x

Gavloski JE, Lamb RJ (2000) Compensation for herbivory in cruciferous plants: Specific responses to three defoliating insects. Environ Entomol 29:1258-1267. https://doi.org/10.1603/0046-225X-29.6. 1258

Gherlenda AN, Haigh AM, Moore BD, Johnson SN, Riegler M (2016) Climate change, nutrition and immunity: Effects of elevated $\mathrm{CO}_{2}$ and temperature on the immune function of an insect herbivore. $\mathbf{J}$ Insect Physiol 85:57-64. https://doi.org/10.1016/j.jinsphys.2015. 12.002

González-Santoyo I, Córdoba-Aguilar A (2012) Phenoloxidase: a key component of the insect immune system. Entomol Exp Appl 142:1-16. https://doi.org/10.1111/j.1570-7458.2011.01187.x
Greeney HF, Dyer LA, Smilanich AM (2012) Feeding by lepidopteran larvae is dangerous: a review of caterpillars' chemical, physiological, morphological, and behavioral defenses against natural enemies. Invertebr Surviv J 9:7-34

Gross P (1993) Insect behavioral and morphological defenses against parasitoids. Annu Rev Entomol 38:251-273. https://doi.org/10. 1146/annurev.en.38.010193.001343

Hall CR, Mikhael M, Hartley SE, Johnson SN (2020) Elevated atmospheric $\mathrm{CO}_{2}$ suppresses jasmonate and silicon-based defences without affecting herbivores. Funct Ecol 34:993-1002. https://doi.org/ 10.1111/1365-2435.13549

Hall CR, Rowe RC, Mikhael M, Read E, Hartley SE, Johnson SN (2021) Plant silicon application alters leaf alkaloid concentrations and impacts parasitoids more adversely than their aphid hosts. Oecologia 196:145-154. https://doi.org/10.1007/ s00442-021-04902-1

Herms DA, Mattson WJ (1992) The dilemma of plants: to grow or defend. Q Rev Biol 67:283-335. https://doi.org/10.1086/417659

Iltis C, Martel G, Thiéry D, Moreau J, Louâpre P (2018) When warmer means weaker: high temperatures reduce behavioural and immune defences of the larvae of a major grapevine pest. J Pest Sci 91:1315-1326. https://doi.org/10.1007/s10340-018-0992-y

Islam T, Moore BD, Johnson SN (2020) Novel evidence for systemic induction of silicon defences in cucumber following attack by a global insect herbivore. Ecol Entomol 45:1373-1381. https://doi. org/10.1111/een.12922

Islam T, Moore BD, Johnson SN (2022) Silicon suppresses a ubiquitous mite herbivore and promotes natural enemy attraction by altering plant volatile blends. J Pest Sci 95:423-434. https://doi. org/10.1007/s10340-021-01384-1

Johnson SN, Reynolds OL, Gurr GM, Esveld JL, Moore BD, Tory GJ, Gherlenda AN (2019) When resistance is futile, tolerate instead: silicon promotes plant compensatory growth when attacked by above- and belowground herbivores. Biol Lett 15:20190361. https://doi.org/10.1098/rsbl.2019.0361

Johnson SN, Rowe RC, Hall CR (2020) Silicon is an inducible and effective herbivore defence against Helicoverpa punctigera (Lepidoptera: Noctuidae) in soybean. Bull Entomol Res 110:417-422. https://doi.org/10.1017/S0007485319000798

Johnson SN, Hartley SE, Ryalls JMW, Frew A, Hall CR (2021a) Targeted plant defense: silicon conserves hormonal defense signaling impacting chewing but not fluid-feeding herbivores. Ecology 102:e03250. https://doi.org/10.1002/ecy.3250

Johnson SN, Waterman JM, Wuhrer R, Rowe RC, Hall CR, CibilsStewart X (2021b) Siliceous and non-nutritious: nitrogen limitation increases anti-herbivore silicon defences in a model grass. J Ecol. https://doi.org/10.1111/1365-2745.13755

Jones CM, Parry H, Tay WT, Reynolds DR, Chapman JW (2019) Movement ecology of pest Helicoverpa: implications for ongoing spread. Annu Rev Entomol 64:277-295. https://doi.org/10. 1146/annurev-ento-011118-111959

Jung H-i, Gayomba SR, Yan J, Vatamaniuk OK (2014) Brachypodium distachyon as a model system for studies of copper transport in cereal crops. Front Plant Sci 5:236. https://doi.org/10.3389/fpls. 2014.00236

Jung HI, Yan J, Zhai Z, Vatamaniuk OK (2015) Gene functional analysis using protoplast transient assays. Methods Mol Biol 1284:433452. https://doi.org/10.1007/978-1-4939-2444-8_22

Kanost MR, Gorman MJ (2008) Phenoloxidases in insect immunity. In: Beckage NE (ed) Insect immunology. Academic Press, San Diego

Koricheva J (2002) Meta-analysis of sources of variation in fitness costs of plant antiherbivore defenses. Ecology 83:176-190. https://doi. org/10.1890/0012-9658(2002)083[0176:MAOSOV]2.0.CO;2

Kvedaras OL, Byrne MJ, Coombes NE, Keeping MG (2009) Influence of plant silicon and sugarcane cultivar on mandibular wear in the 
stalk borer Eldana saccharina. Agric for Entomol 11:301-306. https://doi.org/10.1111/j.1461-9563.2009.00430.x

Lavine MD, Strand MR (2002) Insect haemocytes and their role in immunity. Insect Biochem Mol Biol 32:1295-1309. https://doi. org/10.1016/s0965-1748(02)00092-9

Liu J, Zhu J, Zhang P et al (2017) Silicon supplementation alters the composition of herbivore induced plant volatiles and enhances attraction of parasitoids to infested rice plants. Front Plant Sci 8:1265. https://doi.org/10.3389/fpls.2017.01265

Ma JF, Yamaji N (2006) Silicon uptake and accumulation in higher plants. Trends Plant Sci 11:392-397. https://doi.org/10.1016/j. tplants.2006.06.007

Mandlik R, Thakral V, Raturi G, Shinde S, Nikolić M, Tripathi DK, Sonah H, Deshmukh R (2020) Significance of silicon uptake, transport, and deposition in plants. J Exp Bot 71:6703-6718. https://doi.org/10.1093/jxb/eraa301

Massey FP, Hartley SE (2009) Physical defences wear you down: progressive and irreversible impacts of silica on insect herbivores. J Anim Ecol 78:281-291. https://doi.org/10.1111/j.1365-2656. 2008.01472.x

Massey FP, Ennos AR, Hartley SE (2007) Herbivore specific induction of silica-based plant defences. Oecologia 152:677-683. https:// doi.org/10.1007/s00442-007-0703-5

Moore BD, Johnson SN (2016) Get tough, get toxic, or get a bodyguard: Identifying candidate traits conferring belowground resistance to herbivores in grasses. Front Plant Sci 7:1925. https://doi. org/10.3389/fpls.2016.01925

Moreno-García M, Córdoba-Aguilar A, Condé R, Lanz-Mendoza H (2013) Current immunity markers in insect ecological immunology: assumed trade-offs and methodological issues. Bull Entomol Res 103:127-139. https://doi.org/10.1017/S000748531200048X

Murray TJ, Tissue DT, Ellsworth DS, Riegler M (2013) Interactive effects of pre-industrial, current and future $\left[\mathrm{CO}_{2}\right]$ and temperature on an insect herbivore of Eucalyptus. Oecologia 171:1025-1035. https://doi.org/10.1007/s00442-012-2467-9

Nikpay A, Soleyman-Nejadian E, Goldasteh S, Farazmand H (2015) Response of sugarcane and sugarcane stalk borers Sesamia spp. (Lepidoptera: Noctuidae) to calcium silicate fertilization. Neotrop Entomol 44:498-503. https://doi.org/10.1007/s13744-015-0298-1

Núñez-Farfán J, Fornoni J, Valverde PL (2007) The evolution of resistance and tolerance to herbivores. Annu Rev Ecol Evol 38:541566. https://doi.org/10.1146/annurev.ecolsys.38.091206.095822

Pekas A, Wäckers FL (2020) Bottom-up effects on tri-trophic interactions: plant fertilization enhances the fitness of a primary parasitoid mediated by its herbivore host. J Econ Entomol 113:26192626. https://doi.org/10.1093/jee/toaa204

Piñera AV, Charles HM, Dinh TA, Killian KA (2013) Maturation of the immune system of the male house cricket, Acheta domesticus. J Insect Physiol 59:752-760. https://doi.org/10.1016/j.jinsphys. 2013.05.008

R Core Team (2019) R: A language and environment for statistical computing. R Foundation for Statistical Computing, Vienna, Austria

Reidinger S, Ramsey MH, Hartley SE (2012) Rapid and accurate analyses of silicon and phosphorus in plants using a portable X-ray fluorescence spectrometer. New Phytol 195:699-706. https://doi. org/10.1111/j.1469-8137.2012.04179.x

Remmel T, Davison J, Tammaru T (2011) Quantifying predation on folivorous insect larvae: the perspective of life-history evolution. Biol J Linn Soc 104:1-18. https://doi.org/10.1111/j.1095-8312. 2011.01721.x

Reynolds OL, Padula MP, Zeng R, Gurr GM (2016) Silicon: potential to promote direct and indirect effects on plant defense against arthropod pests in agriculture. Front Plant Sci 7:744. https://doi. org/10.3389/fpls.2016.00744
Ribeiro C, Brehélin M (2006) Insect haemocytes: What type of cell is that? J Insect Physiol 52:417-429. https://doi.org/10.1016/j.jinsp hys.2006.01.005

Scholthof K-BG, Irigoyen S, Catalan P, Mandadi KK (2018) Brachypodium: A monocot grass model genus for plant biology. Plant Cell 30:1673-1694. https://doi.org/10.1105/tpc.18.00083

Shiao SH, Higgs S, Adelman Z, Christensen BM, Liu SH, Chen CC (2001) Effect of prophenoloxidase expression knockout on the melanization of microfilariae in the mosquito Armigeres subalbatus. Insect Mol Biol 10:315-321. https://doi.org/10.1046/j. 0962-1075.2001.00268.x

Singer MS, Stireman JOI (2005) The tri-trophic niche concept and adaptive radiation of phytophagous insects. Ecol Lett 8:12471255. https://doi.org/10.1111/j.1461-0248.2005.00835.x

Siva-Jothy MT (2000) A mechanistic link between parasite resistance and expression of a sexually selected trait in a damselfly. Proc R Soc B 267:2523-2527

Stiling P, Cornelissen T (2005) What makes a successful biocontrol agent? A meta-analysis of biological control agent performance. Biol Control 34:236-246. https://doi.org/10.1016/j.biocontrol. 2005.02.017

Sugiura S (2020) Predators as drivers of insect defenses. Entomol Sci 23:316-337. https://doi.org/10.1111/ens.12423

Teakle RE, Jensen JM (1985) Heliothis punctigera. In: Singh P, Moore RF (eds) Handbook of insect rearing, vol 2. Elsevier, Amsterdam, pp 313-322

Vicari M, Bazely DR (1993) Do grasses fight back? The case for antiherbivore defences. Trends Ecol Evol 8:137-141. https://doi.org/ 10.1016/0169-5347(93)90026-1

Vidal MC, Murphy SM (2018) Bottom-up vs. top-down effects on terrestrial insect herbivores: a meta-analysis. Ecol Lett 21:138-150. https://doi.org/10.1111/ele.12874

Vogelweith F, Thiéry D, Quaglietti B, Moret Y, Moreau J (2011) Host plant variation plastically impacts different traits of the immune system of a phytophagous insect. Funct Ecol 25:1241-1247. https://doi.org/10.1111/j.1365-2435.2011.01911.x

Vogelweith F, Thiéry D, Moret Y, Colin E, Motreuil S, Moreau J (2014) Defense strategies used by two sympatric vineyard moth pests. J Insect Physiol 64:54-61. https://doi.org/10.1016/j.jinsp hys.2014.03.009

Vogelweith F, Moret Y, Monceau K, Thiéry D, Moreau J (2016) The relative abundance of haemocyte types in a polyphagous moth larva depends on diet. J Insect Physiol 88:33-39. https://doi.org/ 10.1016/j.jinsphys.2016.02.010

Wang J, Hüner N, Tian L (2019) Identification and molecular characterization of the Brachypodium distachyon NRT2 family, with a major role of BdNRT2.1. Physiol Plant 165:498-510. https://doi. org/10.1111/ppl.12716

Wilson-Rich N, Dres ST, Starks PT (2008) The ontogeny of immunity: development of innate immune strength in the honey bee (Apis mellifera). J Insect Physiol 54:1392-1399. https://doi.org/ 10.1016/j.jinsphys.2008.07.016

Winde I, Wittstock U (2011) Insect herbivore counteradaptations to the plant glucosinolate-myrosinase system. Phytochemistry 72:15661575. https://doi.org/10.1016/j.phytochem.2011.01.016

Wu X, Yu Y, Baerson SR, Song Y, Liang G, Ding C, Niu J, Pan Z, Zeng $\mathrm{R}$ (2017) Interactions between nitrogen and silicon in rice and their effects on resistance toward the brown planthopper Nilaparvata lugens. Front Plant Sci 8:28. https://doi.org/10.3389/fpls. 2017.00028

Yang S, Ruuhola T, Rantala MJ (2007) Impact of starvation on immune defense and other lifehistory traits of an outbreaking geometrid, Epirrita autumnata: a possible causal trigger for the crash phase of population cycle. Ann Zool Fenn 44:89-96

Zhou J, Meng L, Li B (2017) Defensive behaviors of the Oriental armyworm Mythimna separata in response to different parasitoid 
species (Hymenoptera: Braconidae). PeerJ 5:e3690. https://doi. org/10.7717/peerj.3690

Publisher's Note Springer Nature remains neutral with regard to jurisdictional claims in published maps and institutional affiliations. 